\title{
Água: um olhar feminino
}

Dossier ÁGUA E MULHER

\section{Luciana Cordeiro de Souza-Fernandes}

Professora de Direito. Faculdade de Ciências Aplicadas da Universidade Estadual de Campinas; Programa de Pós Graduação em Ensino e História de Ciências da Terra, Instituto de Geociências, Unicamp. Limeira [São Paulo] Brasil. <luciana.fernandes@fca.unicamp.br>

\section{Resumo}

O presente trabalho traça um panorama da questão da água e a participação da mulher no cuidado com este bem da vida, numa luta diária como provedora ou guerreira para levar à sua família o acesso a este direito fundamental.

\section{Palavras-chave}

Gestão da água. Mulher e água. Força da mulher. Luta pela água.

\section{Water: a feminine view}

\begin{abstract}
The present work traces a panorama of the issue of water and the women participation in the care of this good of life, in a daily struggle as a provider or warrior to bring their family access to this fundamental right.
\end{abstract}

\section{Keywords}

Water management. Woman and water. Woman's strength. Struggle for water. 
1. Introdução

O planeta Terra, lar que nos foi dado para ser administrado e servir de moradia para todos os seus habitantes, pede socorro. Se olharmos ao redor, avistamos poluição, destruição, miséria, fome, doenças e morte.

A água é a fonte da vida e certeza de seu continuar. E de forma gratuita nos oferece sua pureza, além de conferir beleza à paisagem. Somos todos formados de água, filhos da Mãe natureza, compostos dos elementos fogo, terra, ar e água.

Parece incrível que a ligação de duas moléculas de hidrogênio com apenas uma molécula de oxigênio, nos possibilita o existir (Souza, 2008, p. 142).

A Terra é tida como o "planeta água", porém somente 2,7\% desta água é considerada doce! Deste percentual, a água se encontra na forma líquida nos rios, lagos e aquíferos; na forma gasosa nas nuvens; e na forma sólida nas geleiras. Entretanto, espacialmente, estas águas estão distribuídas irregularmente, há regiões com abundância, outras com conforto hídrico, outras com estresse hídrico e outras ainda em condição de escassez. Sendo que nas áreas mais áridas do planeta, além de não contarem com acesso à água, sua população sofre para a obtenção do líquido da vida, buscando-a em lugares distantes, aliado a pobreza que assola estas regiões. Dados da UNEP (2000) revelam que as regiões semi-áridas ocupam $40 \%$ do planeta (Sahel, Austrália, EUA, Rússia, China, Oriente Médio). Ainda, informa que há $40 \%$ da população da África, América do Sul e Ásia vivendo em zonas semi-áridas. E nas zonas semi-áridas do mundo, a mulher pobre é sempre a mais atingida com a falta da água. 0 desenvolvimento sustentável do semi-árido implica na participação equitativa dos sexos nos processos de decisão sobre o destino das águas e o manejo do ecossistema.

No Brasil isto não é diferente, apesar de determos quase 13\% da água doce em forma líquida, sua distribuição territorial também é dispare, fazendo com que ocorram migrações constantes e os que permanecem nas áreas de seca, notadamente no semiárido brasileiro, caminham horas a fio em busca de água para subsistência. E, historicamente, este papel é relegado às mulheres e meninas, que além dos afazeres domésticos, têm a missão de suprir com água sua família. Todavia, o Poder Público e a sociedade encaram com naturalidade esta função destinada à mulher - como provedora da água - em algumas regiões do país.

E ser mulher neste século XXI, nos faz ainda mais responsáveis pelo Planeta, zelando por nossa Casa Planetária como fazemos com nossos lares, educando nossos filhos a olhar com este mesmo cuidado (Souza, 2008, p. 142).

\section{0 simbolismo da água}

E a mulher, de forma privilegiada, durante toda a gestação sente seu filho se formando e crescendo dentro deste líquido precioso, que carrega em si lembranças indeléveis na formação do ser humano, que faz dele eterno viajante em busca da proteção perdida ao nascer. A água envolve e protege (Souza, 2008, p. 143).

De acordo com Silva (1998, p. 21-4), Ferenczi (1990) especula que a origem da estreita vinculação com a água, e da forte presença de suas imagens simbólicas no inconsciente, estaria relacionada tanto à memória intrauterina, como à nossa origem oceânica, podendo ser constatada através dos vários mitos e rituais presentes em diversas religiões. Para o citado autor, parece existir um forte desejo humano de regressão ao líquido amniótico, mas apesar de suas dificuldades em conceituar tal hipótese, ele não abandona o pressuposto de que: [...]

[...] as formações psíquicas mais diversas (sonho, neurose, mito, folclore, etc.) representam por um mesmo símbolo, o coito e o nascimento: ser salvo de um perigo, sobretudo da água (líquido amniótico); do mesmo modo, [...] elas exprimem as sensações experimentadas [...] na existência intra-uterina através das sensações de nadar, flutuar, voar. Um verdadeiro símbolo teria valor de monumento histórico, seria um precursor [...] dos modos de agir pertencentes a uma época superada, portanto restos mnimésicos aos quais somos propensos a retornar, tanto no plano psíquico quanto no físico (Ferenczi apud Silva, p.54). 
Assim, ele intui que fragmentos inteiros de história perdida, ou inacessível por outros meios, estariam conservados como 'hieróglifos' nas formas de expressão simbólicas ou indiretas do psiquismo e do corpo. A partir desta ideia, entrar na água seria como repetir o símbolo mais arcaico, ou seja, o do retorno ao útero materno, e ser salvo ou resgatado das águas representaria o episódio do nascimento, da saída da água para a terra. Fazendo uma analogia com a origem humana remota, o psicanalista Ferenczi (1990) especula sobre a existência de um desejo humano de retornar ao oceano abandonado dos tempos primitivos, ao que denomina de 'regressão talássica' (Silva, 1998, p. 21-4).

Na visão mitológica, a água, da qual o oceano é sem dúvida seu maior símbolo, traz consigo as sementes da vida, os segredos e os fermentos de suas múltiplas formas, além dos medos que às vezes são evocados pelas figuras míticas dela oriundas quando em estado de decomposição (a lama e os pântanos). Schama (1996), assim como Ferenczi, acrescenta que: "ver um rio equivale a mergulhar numa grande corrente de mitos e lembranças, forte o bastante para nos levar ao primeiro elemento aquático de nossa existência intra-uterina. E, com essa torrente, nasceram algumas de nossas paixões sociais e animais mais intensas: as misteriosas transmutações do sangue e da água; a vitalidade e a mortalidade de heróis, impérios, nações e deuses [...] Desde a Antiguidade, se comparava o [...] fluxo [dos rios] à circulação do sangue pelo corpo.", pontua Silva (1998, p. 21-4).

Na Antiguidade, a água, por ser um dos elementos vitais para todas as sociedades, era revestida por um vasto conteúdo simbólico, demonstrando a sua importância na organização das primeiras civilizações situadas nas bacias de grandes rios e nas costas mediterrâneas. 0 elemento aqua, sempre foi inspirador de indagações e motivo de veneração em diferentes culturas antigas de acordo com Silva (1998, p. 21-4).

O poder da água como símbolo na Mitologia egípcia traz que Osíris era a personificação da fecundidade, a fonte total e criadora das águas. 0 Nilo era a fusão de Osíris e Set Tifão a sua antítese, a personificação da aridez e da fome, representando tudo o que era seco e causticante. O Nilo era originado da união entre Osíris aquático e Ísis terrena, da qual nasceu o menino-deus Hórus que, ao eliminar Tifão, obrigou o oceano destruidor a recuar, deixando nas margens do rio Nilo o lodo aluvial que adubava as plantações, discorre o autor (Silva, 1998, p. 23).

0 simbolismo do elemento água também é descrito na Mitologia grega quando da origem da criação grega, Graves (1967) descreve um dos mitos em que, no princípio de tudo, o ar uniu-se ao dia dando o nascimento da Mãe Terra, do Céu e do Mar. Da união do Ar com a Mãe Terra apareceu o Oceano, Métis e outros Titãs. O Mar, por sua vez, uniu-se aos Rios originando as Nereidas. 0 Céu e a Terra (Gaia) eram os símbolos masculino e feminino que, através da fertilização das águas, produziam a vida, a qual passava a ser regida por Eros. Os rios e as fontes, ao serem considerados filhos de Oceanos pelos gregos, eram divinizados e a eles dedicavam oferendas (Silva,1998, p. 24).

E assim temos a água como elemento sacro, ao longo dos séculos, sempre utilizada por todas as religiões como forma de purificação. Do mesmo modo, a história nos conta que para o estabelecimento do homem e a formação das cidades esta mesma água foi o elemento determinador para o início das civilizações as margens dos rios e lagos.

\section{A mulher como provedora da água}

Na divisão sexual de tarefas, é responsabilidade da mulher manter a saúde da família. Todavia, sua posição desigual na sociedade, não permite que tenha as condições para determinar o uso adequado da água ou decidir sobre saneamento (Garcia, 2007, p. 19).

Em publicação no Banco Interamericano de Desenvolvimento - BID (2016), verifica-se um olhar para mulher na perspectiva da água, desde o acesso até a perda de oportunidades pelo tempo despendido para que "mulheres e meninas" supram a família com o líquido da vida, motivo pelo qual, esta temática deve ser incorporada às políticas públicas.

De acordo com o infográfico apresentado na Figura 1, as autoras destacam que no setor de água e saneamento, as políticas públicas precisam incorporar uma perspectiva de gênero para assegurar sua sustentabilidade. Para combater as desigualdades, temos que começar por saber medir a dimensão 
do problema. Embora contemos com muitas informações sobre o acesso a serviços de água e saneamento, os dados sobre a distribuição por sexo são muito escassos. De qualquer modo, é importante incorporar a perspectiva de gênero em nossos projetos, por exemplo, pela capacitação e sensibilização sobre as diferenças nos papéis de gênero ou levando em conta a opinião e necessidades específicas das mulheres durante os processos de tomada de decisão ligados à elaboração e implementação. Isso nos leva à necessidade de ampliar a participação das mulheres no setor: atualmente, as mulheres estão sub-representadas, sendo apenas $19,7 \%$ dos empregados no setor de água e saneamento (em comparação com mais de $60 \%$ no setor de serviços). Portanto, é nossa responsabilidade pôr em marcha ações que promovam uma participação igualitária de homens e mulheres em postos de decisão (de ministérios a comitês comunitários de água), bem como no desenvolvimento de políticas setoriais, planejamento e administração de projetos (Monje; Núñez \& Subiza, 2016).

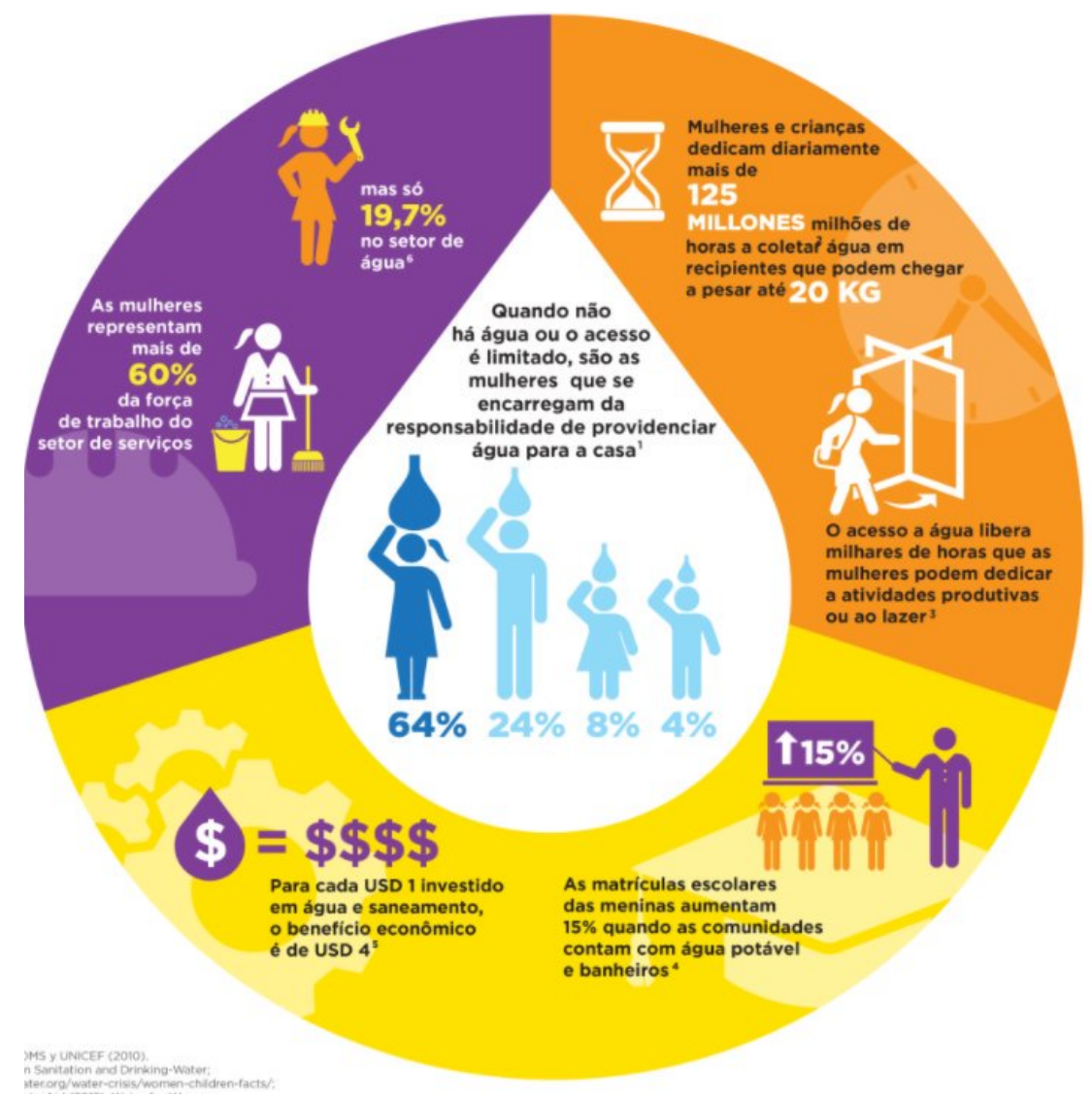

Figura 1. Infográfico. Fonte: BID, 20161

Campos G. (2016), chefe da Divisão de Água e Saneamento do BID, compara a ida do homem à lua com as mulheres de um país como a África do Sul, que ainda caminham diariamente o equivalente a 16 vezes a distância de ida e volta à lua para obter a água de que suas famílias precisam para sobreviver.

O papel tradicional das mulheres no lar explica por que os homens dedicam mais tempo a atividades remuneradas e as mulheres se ocupam dos afazeres domésticos, um trabalho essencial para o funcionamento de nossa sociedade, mas com muito pouco reconhecimento e nenhuma remuneração monetária. Por isso, quando não há serviço de água (ou quando este é limitado), as mulheres no mundo, principais usuárias, prestadoras e administradoras dos serviços, passam mais de seis horas diárias buscando água e fervendo-a para beber, cozinhar, dar banho nos filhos, limpar a casa e lavar a roupa, em vez de ir à universidade, trabalhar ou descansar. E, pior ainda, as mulheres e meninas que não têm um banheiro

\footnotetext{
1 Fontes: 1. OMS y UNICEF (2010); Progress on Sanitation and Drinking-Water; 2. http://water.org/water-crisis/ women-children-facts/; 3, 4 y 5. WaterAid (2015). Water for Women; 6. Encuestas de Hogar.
} 
precisam caminhar grandes distâncias, sozinhas, muitas vezes à noite, para evitarem de serem vistas e/ou assediadas ao serem obrigadas a defecar ao ar livre, o que atenta contra sua dignidade e segurança pessoal.

Em termos de educação, uma em cada quatro meninas no mundo não termina a escola primária, em comparação com um a cada sete meninos. Isso se deve, em parte, ao fato de que, em muitos casos, as escolas não têm banheiros e, quando estes existem, em geral não atendem às necessidades das meninas, que se vêm obrigadas a se ausentar das aulas no período da menstruação. Em termos de mercado de trabalho, as perdas são alarmantes: na África subsaariana, 40 bilhões de horas são perdidas a cada ano pela necessidade de transportar água, o que equivale a um ano inteiro de trabalho de toda a força de trabalho da França. E, quando pensamos que, no mundo, 70\% das pessoas que vivem em situação de pobreza são mulheres, que assumem grande parte das tarefas não remuneradas da casa, entendemos por que a água e o saneamento são elementos fundamentais para a sustentabilidade das políticas de inclusão social (Campos G, 2016).

Todos estes dados retratam um cenário de ausência de saneamento, que compromete, sobretudo, o futuro das meninas, que inferiorizadas, sem direitos de sonhar, apenas vivem para servir, lutando pela sobrevivência de suas famílias acima de sua própria sobrevivência. É como que, a depender da localização geográfica de onde elas nasçam seus destinos já estão traçados.

No Brasil, o cenário não é diferente, milhares e milhares de mulheres e meninas caminham horas e horas em busca de água, com a lata d'água na cabeça, numa reprodução de sua herança histórica, como se não houvesse outra função para suas existências.

Vivemos no século XXI, a revolução tecnológica é imensa, há aparelhos de televisão e de telefonia móvel em quase todos os lares do país, porém não há água ou esgotamento sanitário nestas mesmas casas. Parece-nos uma antítese do "progresso", quando constatamos que "4 Milhões de habitantes no Brasil, ainda não têm acesso a banheiro" (Tratabrasil, 2017).

Importa ressaltar que na legislação brasileira saneamento não diz respeito tão somente à coleta e tratamento de esgoto, mas um conjunto de atividades ligadas à qualidade de vida, promovendo saúde e dignidade a pessoa humana, descritos no art. 3ํ da Lei 11445/2007, in verbis,

Art. 3ํㅜㄹ Para of eitos desta Lei, considera-se:

I - saneamento básico: conjunto de serviços, infra-estruturas e instalações operacionais de:

a) abastecimento de água potável: constituído pelas atividades, infra-estruturas e instalações necessárias ao abastecimento público de água potável, desde a captação até as ligações prediais e respectivos instrumentos de medição;

b) esgotamento sanitário: constituído pelas atividades, infra-estruturas e instalações operacionais de coleta, transporte, tratamento e disposição final adequados dos esgotos sanitários, desde as ligações prediais até o seu lançamento final no meio ambiente;

c) limpeza urbana e manejo de resíduos sólidos: conjunto de atividades, infra-estruturas $e$ instalações operacionais de coleta, transporte, transbordo, tratamento e destino final do lixo doméstico e do lixo originário da varrição e limpeza de logradouros e vias públicas;

d) drenagem e manejo das águas pluviais, limpeza e fiscalização preventiva das respectivas redes urbanas: conjunto de atividades, infraestruturas e instalações operacionais de drenagem urbana de águas pluviais, de transporte, detenção ou retenção para o amortecimento de vazões de cheias, tratamento e disposição final das águas pluviais drenadas nas áreas urbanas; (Brasil, 2007).

Assim, o abastecimento de água e com qualidade é um serviço de saneamento a que toda população brasileira deve ter acesso, trata-se de um direito de todos e dever do Estado proporcionar acesso a este direito básico e essencial.

De acordo com a Organização Mundial para Saúde, 80\% das doenças são de origem hídrica. A água contaminada mata 5700 crianças a cada dia, uma em cada 15 segundos. 
No Brasil, 22,6 milhões de pessoas não têm acesso a água tratada. Uma criança no Piauí tem 48 vezes menos acesso a água potável que uma criança em São Paulo. As crianças negras e índias têm 3 vezes menos acesso que as crianças brancas. Entre os mais pobres, $35 \%$ não têm acesso água, entre os ricos este número cai para 0,5\%. É possível constatar a extrema desigualdade do país refletida nas condições de acesso e uso dos recursos hídricos (Garcia, 2007, p. 19).

Em números mais atualizados sobre o saneamento, de acordo com o Instituto Trata Brasil (2017), 83,3\% dos brasileiros são atendidos com abastecimento de água tratada, correspondendo a mais de 35 milhões de brasileiros sem o acesso a este serviço básico. Sendo que a região Sudeste apresenta $91,24 \%$ de atendimento total de água; enquanto isso, a região Norte apresenta índice de $55,37 \%$. Somente 51,92\% da população têm acesso à coleta de esgoto, ou seja, mais de 100 milhões de brasileiros não tem acesso a este serviço. Significando dizer que mais de 3,5 milhões de brasileiros, nas 100 maiores cidades do país, despejam esgoto irregularmente, mesmo tendo redes coletoras disponíveis. Entretanto, a situação é mais preocupante, pois 44,92\% dos esgotos do país são tratados. A média das 100 maiores cidades brasileiras em tratamento dos esgotos foi de $50,26 \%$, e apenas 10 delas tratam acima de $80 \%$ de seus esgotos. Na distribuição destes percentuais pelas Regiões do Brasil, foram identificados cenários assustadores: a Região Norte trata apenas $18,3 \%$ do esgoto e o índice de coleta é de $10,45 \%$, é a pior situação entre todas as regiões. A região Nordeste tem apenas $36,22 \%$ do esgoto tratado, com índice de coleta de $26,79 \%$. Na região Sudeste $48,8 \%$ do esgoto é tratado e o índice de atendimento total de esgoto é de $78,57 \%$. Na região Sul 43,87\% do esgoto é tratado e o índice de atendimento total de esgoto coletado é de $42,46 \%$. Já na região Centro-Oeste $52,62 \%$ do esgoto é tratado, e apesar desta região ser considerada com melhor desempenho, porém a média de esgoto tratado ainda é de 51,52\%.

\section{A luta de mulheres pela água na América Latina}

Com seu ciclo hidrológico perfeito, a água passa do seu estado gasoso para o líquido, do líquido para o sólido, e, assim, continuamente está sempre se renovando, se purificando. A água conhece seus estados físicos e se adapta ao meio e as situações controversas, e a mulher com sua percepção aguçada do meio, está aprendendo também a conhecer seu próprio "ciclo hidrológico" como mãe, esposa, profissional, filha, irmã, neta, avó, estudante, amiga, patroa, empregada, guerreira, em todos os papéis como mulher (Souza, 2008, p. 144).

A participação da mulher não se limita a apenas prover sua família deste líquido da vida e ou da realização de afazeres domésticos, pois a mulher é forte e luta pela vida com "força uterina', dizem alguns; ou simplesmente o faz em razão de sua sensibilidade, dizem outros, seja por qual motivo for, podemos destacar dois grandes momentos de luta, de verdadeiras guerras pela água ocorridas na Bolívia e no México, que tiveram como protagonistas as mulheres, líderes pela vida.

\subsection{Na Bolívia}

El acontecimiento denominado "Guerra del Agua de Cochabamba" es un caso muy revelador acerca de la problemática del agua en el mundo, puesto que a través de él se ha logrado examinar a fondo temas muy importantes como la privatización de los servicios de agua potable, las condiciones establecidas por la cooperación para los créditos, los niveles de pobreza vinculados al acceso del agua potable, la participación y el conflicto social. El caso es ilustrativo con relación a problemáticas rurales y urbanas y sus alianzas para defender el derecho al agua y a la vida (Udaeta, 2001).

Segundo a autora (2001), durante a década de 1980 os Estados latino-americanos emitiram normativas que garantiam o amplo funcionamento da globalização financeira. Na década de 1990 aplicaram e ajustaram reformas estatais macroestruturais, principalmente de ordem econômica, significando redução das competências do Estado a um rol normativo e regulador para o livre mercado; desprezando seus princípios, deveres e obrigações constitucionais nas esferas pública e privada. Promoveram-se alterações na forma de gestão e privatização dos serviços e da propriedade sobre os recursos naturais, reestruturando o marco legal e institucional para dar vez a criação de monopólios privados em uma economia de livre mercado que não poderia garantir crescimento com equidade gerando conflitos sociais. E na Bolívia isto não foi diferente, cedendo a pressões internacionais, 
$[\ldots]$

En octubre de 1999, Bolivia en el marco de los compromisos acordados con el Banco Mundial opera la privatización de la empresa de agua SEMAPA, prestadora pública municipal de servicios de agua potable y alcantarillado sanitario, otorgando una Concesión al Consorcio "Aguas del Tunari", subsidiaria de la Multinacional Bechtel para la explotación de fuentes de agua y prestación del servicio de agua potable, concesión que abarcaba a toda la ciudad de Cochabamba, área que incluía la presencia de pequeños productores rurales y pequeños sistemas autogestionarios de agua potable que con esta medida eran afectados em sus derechos. Por otro lado el Contrato también garantizaba a la compañía una tasa de retorno de su inversión del 15\%, para lo cual se garantizaba que las tarifas se indexarían según el índice de precios al consumidor en los Estados Unidos.

Un poco después de la firma de contrato de concesión que privatiza SEMAPA se aprueba la Ley No. 2029 (octubre de 1999) de "Prestación de Servicios de Agua Potable y Alcantarillado Sanitario", de forma inconsulta provoca la reacción de los pobladores urbanas y rurales que se traduce en un bloqueo de caminos en noviembre de 1999, obligando a las autoridades de Gobierno a negociar, producto de ésta se firma un Convenio entre la Superintendencia de Saneamiento Básico y las organizaciones sociales y campesinas, en el que se les garantizaba que el Consorcio Aguas del Tunari respetaría sus fuentes de agua. No obstante, la Ley № 2029 quedaba intacta y era urgente su modificación.

A partir de enero a abril del 2000 se desencadena un proceso de movilización hasta lograr la modificación de la Ley y la expulsión de la Empresa Aguas del Tunari, por los graves abusos (elevación de tarifas excesiva, por ejemplo) cometidos en contra de la población. La Federación Departamental Cochabambina de Organizaciones de Regantes (FEDECOR) integrante de la Coordinadora departamental de Cochabamba de Defensa del Agua y de la

Vida, constituye uno de los actores centrales del movimiento "guerra del agua". Esta movilización es violentamente reprimida y se origina un conflicto de mayor proporción que culmina con hechos de sangre y la firma de un nuevo acuerdo: "Convenio por Cochabamba", en el que el gobierno se compromete a congelar las tarifas de agua al nivel de 1998 en tanto se llegue a un acuerdo. Sin embargo, las negociaciones se estancan, hasta que la Coordinadora convoca en los primeros días de Abril a un paro total de actividades y la "toma pacífica de la ciudad de Cochabamba", dando así inicio a la denominada "Batalla Final" de la guerra por el agua, y a las dos semanas más dramáticas de la historia boliviana de los últimos años (Udaeta, 2001).

Cochabamba é um estado marcado pela falta de água na maioria de suas comunidades, sendo que somente $55 \%$ da população urbana e $46 \%$ da rural tem acesso aos sistemas de água potável e esgoto em menor proporção. Então, o problema principal é a escassez de água, portanto está profundamente enraizada nas populações rurais e urbanas uma defesa sobre os seus direitos de água contra qualquer ameaça interna ou externa.

Mientras no se mitigue la filosofía del libre mercado que ejerce su influencia en el diseño de políticas, leyes y normas traducidas en estrategias económicas, sociales, políticas y culturales del país, que superen la pobreza en que se debate el país. "La reducción de la desigualdad del género es no solamente una meta por derecho propio sino tambien uma contribución importante hacia el desarrollo sustentable" (Cuarta Conferencia Mundial sobre la Mujer, Plataforma para la Acción, 1995).

El caso de estudio sobre la "Guerra del agua" y la participación de las mujeres a partir de la promulgación de la Ley de Servicios de Agua Potable y Alcantarillado Sanitario (Ley № 2029) desnuda la visión que se tiene sobre el rol de la mujer como agente-usuaria universal, en áreas urbano marginales y rurales para acceder al agua potable, abstrayendo los otros usos simultáneos del agua (riego, bebedero de animales, usos rituales y medicinales), conclui Udaeta (2001).

De acordo com Bertelli et al (2015), [...]

[...] Derramaron sangre para no quedarse sin agua. Era el año 2000 y los ciudadanos de Cochabamba se pusieron en pie de guerra contra la privatización de sus escasos recursos 
hídricos. Hoy, 15 años después, la lucha diaria por el acceso al agua continúa en la cuarta ciudad más grande de Bolivia.

A instancias del Banco Mundial y del Fondo Monetario Internacional, Bolivia se encontraba hace 15 años en plena oleada de privatizaciones. Para conceder un crédito al gobierno de Banzer, las instituciones de Bretton Woods habían pedido la venta de las compañías públicas de agua de las principales ciudades del país. Semapa, la empresa municipal de agua potable y alcantarillado de Cochabamba, pasó a manos de un consorcio internacional llamado Aguas del Tunari. Este conglomerado - formado por las compañias estadounidenses Bechtel y Edison, la española Abengoa y las bolivianas Petrovich y Doria Medina-, decretó, de la noche a la mañana, un incremento en las tarifas de entre el 30\% y el 300\%.

Además, para blindar los intereses de las multinacionales, el parlamento aprobó la Ley 2029, que abría la puerta para que estas nuevas empresas cobraran por el uso particular de los acuíferos públicos y para que los ciudadanos tuvieran que hacer frente a sus deudas con sus bienes inmuebles. Sobre el papel, esto significaba que Aguas del Tunari podía cobrar por el agua que los vecinos obtuvieran de sus pozos, del río o incluso recogieran de la lluvia, y que si éstos no pagaban estaba autorizada a desahuciarles y quedarse con sus casas. (grifo nosso)

“Con esta ley no sólo se privatizaba el sistema público de agua, sino que también se privatizaban los pequeños sistemas autónomos que dan abastecimiento a un $60 \%$ de la ciudad", explica Marcela. "Estas dos medidas pasan al principio desapercibidas para la población. Son los campesinos los que vienen a la ciudad y alertan a la ciudadanía sobre lo que está pasando".

A guerra trouxe uma vitória, o contrato com a empresa Aguas del Tunari foi revogado, as mulheres foram a luta, mas ainda há muito por fazer naquele país, para que todos tenham acesso a água.

[...] las movilizaciones sociales no podían ser controladas por parte del goberno, quien decide rescindir el contrato, argumentando "razones de fuerza mayor" y dar paso a la modificación de la Ley № 2029, que se convierte en la actual Ley №. 2066 y recoge las principales demandas planteadas por las poblaciones rurales y urbanas, entre ellas se recupera el carácter público de la empresa de agua SEMAPA, con más participación y control social en su directorio. Se modifican 36 artículos de la Ley 2029, para estabelecer garantía al funcionamiento de los sistemas autogestionarios de agua potable, el reconocimiento de los derechos de indígenas y campesinos a sus fuentes de agua y sistema de agua potable, el control social sobre Contratos y revisiones tarifarias, entre otras reivindicaciones

Por su parte la Empresa Aguas del Tunari, plantea una demanda a la Corte Internacional de Controversias sobre Inversiones de La Haya, por 25 millones de dólares de indemnización por la ruptura del Contrato en el 2000. A fines del 2005 la Empresa vende sus acciones (80\%) al Gobierno de Bolivia en un monto simbólico de Bs. 2.00 (0.25 \$us.) (Udaeta, 2001).

\subsection{No México}

En septiembre de 2003, campesinos mazahuas de Villa de Allende, Estado de México sufrieron inundaciones en 300 hectáreas de cultivo por el desbordamiento del río Malacatepec proveniente de la presa de Villa Victoria, del sistema Cutzamala. Esta fue la razón para que los campesinos se organizaran para exigir el pago de sus cultivos. Al cabo de tres meses de espera, en febrero de 2004, los mazahuas iniciaron una serie de acciones colectivas y se constituyeron como el Frente para la Defensa de los Derechos Humanos y Recursos Naturales del Pueblo Mazahua. Después de un año de movilizaciones surgió el Ejército Zapatista de Mujeres em Defensa del Agua, el cual tuvo un importante impacto mediático que logró ejercer presión política ante las instancias involucradas, para beneficio del movimento (Gomèz-Fuentes, 2009, p.207).

No México, a luta pela água foi liderada pelos mazahuas, único grupo indígena da Villa de Allende, pois em razão da inundação de suas terras, sem que nenhuma providência para solucionar o problema fosse adotada, e em contato com um advogado peticionaram além dos danos ocasionados aos terrenos inundados, o fornecimento de água potável para as comunidades, a restituição de 
terras expropriadas pela Comissão Nacional de Água que foram utilizadas pelo sistema Cutzamala e um plano de desenvolvimento sustentável para a região. Ao longo de 2004 diversas reuniões e manifestações se sucederam com promessas de acordo não cumpridas, e como os homens em alguns momentos empenharam sua palavra, a comunidade decidiu que as mulheres iriam à luta.

El principal argumento que las mujeres utilizaron el 20 de septiembre de 2004, en su primer día de manifestación "visible", fue la amenaza de pasar de las acciones pacíficas que habían realizado los hombres, a las acciones violentas que ellas estaban dispuestas a ejecutar si no se atendían sus demandas. Ante los médios de comunicación explicaron que durante la noche del 19 de septiembre realizaron una reflexión en la cual evaluaron la participación de los hombres. Según el argumento preparado por el asesor, las mujeres decidieron que tenían que intervenir y tomar las rendas del movimiento ya que los hombres, con sus acciones pacíficas, no habían tenido éxito.

El 24 de septiembre, alrededor de 60 mujeres se constituyeron como un ejército y se autonombraron Ejército Zapatista de Mujeres por la Defensa del Agua (EZMDA). Ese mismo día construyeron um cuartel a las afueras de la planta potabilizadora, el cual, con el paso del tiempo, se convirtió en un lugar de reunión y deliberación para los participantes en la movilización. Mostraron su forma de organización, armadas simbólicamente con armas de madera y herramientas de labranza, marcharon en pequeños batallones alrededor de las instalaciones y quemaron um maniquí vestido con el uniforme de la CNA. Durante este día las mujeres marcharon en las inmediaciones de la potabilizadora para demostrar ante los médios de información su determinación y sus estratégias militares. Esta nueva organización contaba con once comandantas quienes iban al frente y dirigían las acciones, vestían con el traje mazahua y portaban armas de madera. El rango de comandantas se puede suponer que surgió como reminiscencia de las comandantas del EZLN, tan reconocidas en ese movimento (Gomèz-Fuentes, 2009, p. 210-11).

Com a participação das mulheres, a imprensa nacional e internacional deu visibilidade à luta, a presença da mulher ao lado de seus filhos e empunhando armas talhadas em madeira, retratavam a imagem forte e materna da mulher pela luta de bem estar físico, social e econômico para suas famílias. E elas declararam a imprensa que estavam ali por seus filhos e que dariam a vida pela causa, se necessário fosse. Esta luta das mazahuas, constituindo a Frente Mazahua despertou outras mulheres que se uniram ao movimento, pois também buscavam água para suas famílias.

La construcción de la demanda de un plan integral de desarrollo sustentable para la zona significó, en términos generales, demandar una mejor calidad de vida para los pobladores de la zona mazahua. Las mujeres hicieron suya la demanda de un plan de desarrollo sustentable,el cual consistía en dotar de agua potable a las comunidades, construir y equipar centros de salud y escuelas, generar empleo, un programa de vivienda, y acciones para el cuidado del medio ambiente (Gomèz-Fuentes, 2009, p. 212).

Segundo a autora, a Frente Mazahua e o EZMDA contavam com 10 comandantes mulheres que participaram desde o início do movimento. A Frente Mazahua tinha representantes mulheres, que apesar de não serem comandantes foram líderes de suas comunidades. As bases de apoio de Frente Mazahua estavam formadas por mulheres e homens de distintas comunidades. E apesar do movimento, elas ainda tinham que cuidar de suas casas, seus filhos e maridos, além da discriminação dos machistas. Mas apesar dos dissabores experenciados por elas nesta luta, as mulheres mazahuas haviam obtido êxitos reconhecidos, sua participação havia se convertido em uma forma de luta social que havia beneficiado, estrategicamente, o movimento EZMDA. E conclui Goméz-Fuentes, [...]

[...] A pesar que las mujeres inicialmente no tomaron el mando dentro de la organización, lograron ocupar un lugar en la conciencia social de diferentes organizaciones políticas, de mujeres, ambientalistas, e indígenas.

La estrategia de poner al frente a las mujeres en esta ocasión tuvo un efecto positivo y alentador, con su actuación e imagen el Frente Mazahua revitalizó su lucha y logró conseguir sus objetivos sin llegar a la violencia. La estrategia de resaltar a las mazahuas como madres impactó aún más a la opinión pública, pues las mazahuas no solamente son mujeres,

(c) Labor \& Engenho, Campinas [SP] Brasil, v.12, n.2, p.182-196, abr./jun. 2018. 
sino madres, indígenas y pobres (Gomèz-Fuentes, 2009, p. 220).

Este caso do México confirma que homens e mulheres devem lutar juntos pela busca da qualidade de vida, que a mulher não deve ficar em segundo plano e que o êxito da Frente Mazahua se deu em razão do protagonismo dado as mulheres.

\section{A mulher e a água na Agenda 21 Global}

O protagonismo demonstrado pelas mulheres na Bolívia e México inspira mulheres de todas as classes sociais a também lutarem pela água, posto que o acesso e a escassez se aproximam em todos os rincões do planeta. Neste sentido a Agenda 21 Global (1992), enfatiza no capítulo 18 que $[\ldots]$

\section{[...] Da Agenda 21 - Água doce Capítulo 18: \\ "O manejo dos Recursos Hídricos baseia-se na consciência da água como parte do ecossis- tema, recurso natural e bem econômico e social. É recurso finito, altamente vulnerável, de- ve ser gerido com critérios integrados com o desenvolvimento e o manejo ecossistêmico". \\ "A gestão da bacia não abrange só o corpo da água, mas solo e vegetação, regular o uso, as descargas nos rios e regulação da oferta e demanda de água".}

E no Capítulo 24, declara que a comunidade internacional endossou vários planos de ação e convenções para a integração plena, equitativa e benéfica da mulher em todas as atividades relativas ao desenvolvimento, em particular, as Estratégias Prospectivas de Nairóbi para o Progresso da Mulher1/, que enfatizam a participação da mulher no manejo nacional e internacional dos ecossistemas e no controle da degradação ambiental. Aprovaram-se várias convenções, como a Convenção sobre a Eliminação de Todas as Formas de Discriminação contra a Mulher (resolução 34/180 da Assembleia Geral, anexo) e convenções da OIT e da UNESCO, para acabar com a discriminação baseada no sexo e assegurar à mulher o acesso aos recursos de terras e outros recursos, à educação e ao emprego seguro e em condições de igualdade. Também são pertinentes a Declaração Mundial sobre a Sobrevivência, a Proteção e o Desenvolvimento da Criança, de 1990, e seu Plano de Ação (A/45/625, anexo). A implementação eficaz desses programas dependerá da participação ativa da mulher nas tomadas de decisões políticas e econômicas e será decisiva para a implementação bem sucedida da Agenda 21 Global.

\subsection{Mulher e água nos Objetivos de Desenvolvimento Sustentável — ODS}

Outrossim, nos Objetivos de Desenvolvimento Sustentável - ODS, destacam-se os Objetivos 5 e 6 (Figura 2), que confirmam esta necessidade do protagonismo da mulher na gestão da água.
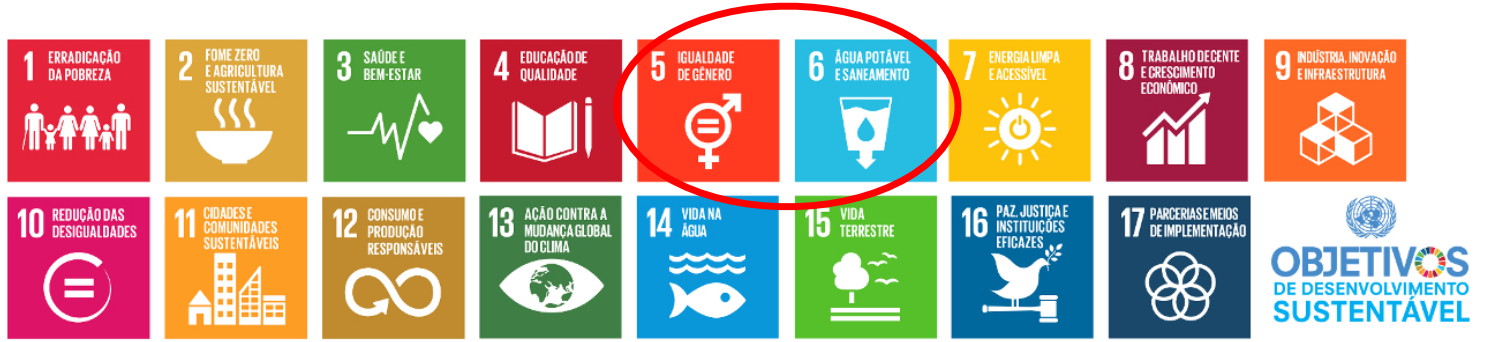

Figura 2. ODS 2030. Fonte: ONU, 2018.

No tocante ao Objetivo 5 - "Alcançar a igualdade de gênero e empoderar todas as mulheres e meninas", diversas são as ações e atividades, com destaque para, em linhas gerais:

Acabar com todas as formas de discriminação contra todas as mulheres e meninas em toda parte;

Eliminar todas as formas de violência contra todas as mulheres e meninas nas esferas públicas e privadas, incluindo o tráfico e exploração sexual e de outros tipos;

Eliminar todas as práticas nocivas, como os casamentos prematuros, forçados e de crianças e mutilações genitais femininas; 
Reconhecer e valorizar o trabalho de assistência e doméstico não remunerado, por meio da disponibilização de serviços públicos, infraestrutura e políticas de proteção social, bem como a promoção da responsabilidade compartilhada dentro do lar e da família, conforme os contextos nacionais;

Garantir a participação plena e efetiva das mulheres e a igualdade de oportunidades para a liderança em todos os níveis de tomada de decisão na vida política, econômica e pública;

Assegurar o acesso universal à saúde sexual e reprodutiva e os direitos reprodutivos, como acordado em conformidade com o Programa de Ação da Conferência Internacional sobre População e Desenvolvimento e com a Plataforma de Ação de Pequim e os documentos resultantes de suas conferências de revisão;

Realizar reformas para dar às mulheres direitos iguais aos recursos econômicos, bem como o acesso a propriedade e controle sobre a terra e outras formas de propriedade, serviços financeiros, herança e os recursos naturais, de acordo com as leis nacionais;

Aumentar o uso de tecnologias de base, em particular as tecnologias de informação $e$ comunicação, para promover o empoderamento das mulheres; $e$,

Adotar e fortalecer políticas sólidas e legislação aplicável para a promoção da igualdade de gênero e o empoderamento de todas as mulheres e meninas em todos os níveis (ONU, 2015).

E sobre a questão da água, o item 24.3, determina atividades a serem seguidas pelos Governos, para que se dediquem ativamente na implementação de programas para promoção da redução do grande volume de trabalho das mulheres e meninas no lar e fora de casa, mediante o estabelecimento de mais creches e jardins de infância de custo acessível por Governos, autoridades locais, empregadores e outras organizações pertinentes e por meio da distribuição equitativa das tarefas domésticas entre o homem e a mulher; e para promover a provisão de tecnologias ambientalmente saudáveis que tenham sido elaboradas, desenvolvidas e aperfeiçoadas em consultas à mulher, o abastecimento de água salubre, o fornecimento de combustível eficiente e de instalações sanitárias adequadas (Agenda 21 Global,1992).

Quanto ao Objetivo 6 - "Assegurar a disponibilidade e gestão sustentável da água e saneamento para todos", inúmeros os dispositivos que se revestem como ações, atividades correlacionando a questão da gestão e manejo da água com a participação da mulher, que a seguir colacionamos: [...]

18.90 manejo integrado dos recursos hídricos, inclusive a integração de aspectos relacionados à terra e à água, deve ser feito ao nível de bacia ou sub-bacia de captação. Quatro objetivos principais devem ser perseguidos:

(c) Traçar, implementar e avaliar projetos e programas que sejam economicamente eficientes e socialmente adequados no âmbito de estratégias definidas com clareza, baseadas numa abordagem que inclua ampla participação pública, inclusive da mulher, da juventude, dos populações indígenas e das comunidades locais, no estabelecimento de políticas e nas tomadas de decisão do manejo hídrico; (grifo nosso).

18.12 Todos os Estados, segundo sua capacidade e disponibilidade de recursos, e por meio de cooperação bilateral ou multilateral, inclusive das Nações Unidas e outras organizações pertinentes, quando apropriado, podem implementar as seguintes atividades para melhorar o manejo integrado dos recursos hídricos:

(n) Desenvolver técnicas de participação do público e implementá-las nas tomadas de decisão, fortalecendo em particular o papel da mulher no planejamento e manejo dos recursos hídricos; (grifo nosso).

18.19. Para delegar o manejo dos recursos hídricos ao nível adequado mais baixo é preciso educar e treinar o pessoal correspondente em todos os planos e assegurar que a mulher participe em pé de igualdade dos programas de educação e treinamento. Deve-se dar particular ênfase à introdução de técnicas de participação pública, inclusive com a intensificação do papel da mulher, da juventude, das populações indígenas e das comunidades locais. Os conhecimentos relacionados com as várias funções do manejo da água devem ser desenvolvidos por Governos municipais e autoridades do setor, bem 
como no setor privado, organizações não-governamentais locais/nacionais, cooperativas, empresas e outros grupos de usuários de água. É necessária também a educação do público sobre a importância da água e de seu manejo adequado. (grifo nosso).

18.22. Ao criar um meio que propicie o manejo nível adequado no nível mais baixo, o papel do Governo inclui a mobilização de recursos financeiros e humanos, a legislação, o estabelecimento de diretrizes e outras funções normativas, o monitoramento e a avaliação do uso dos recursos hídricos e terrestres e a criação de oportunidades para a participação pública. Os organismos e doadores internacionais têm um papel importante a desempenhar na oferta de apoio aos países em desenvolvimento para que criem o meio propício ao manejo integrado dos recursos hídricos. Isso deve incluir, quando apropriado, apoio dos doadores aos níveis locais dos países em desenvolvimento, tais como insti-tuições comunitárias, organizações não governamentais e grupos de mulheres. (grifo nosso).

\subsection{Recomendam-se as seguintes ações:}

(b) Estabelecer e intensificar programas de educação e treinamento sobre tópicos relacionados com a água, dentro de um contexto ambiental e desenvolvimentista, para todas as categorias de pessoal envolvido em atividades de avaliação dos recursos hídricos, usando tecnologia educacional avançada, quando apropriada, e envolvendo tanto homens quanto mulheres; (grifo nosso).

18.34. A condução da avaliação dos recursos hídricos com base em redes hidrométricas nacionais operacionais requer um ambiente propício em todos os planos. As seguintes medidas de apoio são necessárias para fomentar a fortalecimento institucional nacional:

(d) Reforço da capacidade de manejo dos grupos de usuários de água, inclusive mulheres, jovens, populações indígenas e comunidades locais, para melhorar a eficiência do uso da água no plano local; (grifo nosso).

18.45. Entre as abordagens adequadas estão o fortalecimento $\boldsymbol{e}$ o aperfeiçoamento dos recursos humanos de que dispõem os Governos locais para gerenciar a proteção, o tratamento e o uso da água, particularmente em áreas urbanas, e a criação de cursos técnicos e de engenharia nacionais e regionais sobre proteção e controle da qualidade da água em escolas existentes e cursos de treinamento/educação sobre proteção e conservação de recursos hídricos para técnicos de campo e de laboratório, mulheres $e$ outros grupos de usuários da água. (grifo nosso).

18.48. A Declaração de Nova Delhi (adotada na Reunião Consultiva Mundial sobre Água Salubre e Saneamento para a década de 1990, realizada em Nova Delhi de 10 a 14 de setembro de 1990) formalizou a necessidade de oferecer, em base sustentável, acesso à água salubre em quantidade suficiente e saneamento adequado para todos, enfatizando a abordagem de "algum para todos em vez de mais para alguns". Quatro princípios norteadores orientam os objetivos do programa:

(b) Reformas institucionais que promovam uma abordagem integrada e incluam mudanças em procedimentos, atitudes e comportamentos e a participação ampla da mulher em todos os níveis das instituições do setor; (grifo nosso).

18.50. Todos os Estados, segundo sua capacidade e recursos disponíveis e por meio de cooperação bilateral ou multilateral, inclusive as Nações Unidas e outras organizações pertinentes, quando apropriado, podem implementar as seguintes atividades:

(b) Pessoas e instituições:

(iv) Desenvolver os recursos humanos em todos os níveis, incluindo programas especiais para a mulher; (grifo nosso).

(c) Manejo nacional e comunitário:

(ii) Estimular a população local, especialmente as mulheres, os jovens, os populações indígenas e as comunidades locais, a participar do manejo da água; (grifo nosso). 
18.53. Para planejar e gerenciar com eficácia o abastecimento de água e o saneamento nos planos nacional, provincial, distrital e comunitário, e para utilizar mais eficazmente os fundos, deve-se capacitar pessoal profissional e técnico em cada país em número suficiente. Para tanto, os países devem traçar planos de desenvolvimento de recursos humanos, levando em consideração os requisitos atuais e o desenvolvimento planejado. Posteriormente, deve-se intensificar o desenvolvimento e a performance das instituições nacionais de treinamento, a fim de que possam desempenhar um papel central na fortalecimento institucional. É também importante que os países forneçam treinamento adequado às mulheres na manutenção sustentável de equipamento, gestão de recursos hídricos e saneamento ambiental. (grifo nosso).

18.54. A implementação de programas de abastecimento de água é uma responsabilidade nacional. Em graus variados, a responsabilidade pela implementação de projetos e pelo funcionamento dos sistemas deve ser delegada a todos os níveis administrativos, até às comunidades e indivíduos servidos. Isso significa também que as autoridades nacionais, junto com as agências e organismos das Nações Unidas e outras instituições que prestam apoio externo aos programas nacionais, devem desenvolver mecanismos e procedimentos para colaborar em todos os níveis. Isso é particularmente importante para aproveitar ao máximo as abordagens baseadas na comunidade e na própria capacidade desta como instrumentos para a obter a sustentabilidade. Isso exigirá um alto grau de participação comunitária, inclusive da mulher, na concepção, planejamento, decisões, implementação e avaliação relacionados com projetos de abastecimento de água e saneamento. (grifo nosso).

18.59. Todos os Estados, segundo sua capacidade e recursos disponíveis, e por meio de cooperação bilateral ou multilateral, inclusive com as Nações Unidas e outras organizações pertinentes, quando apropriado, podem implementar as seguintes atividades:

(f) Acesso melhor aos serviços de saneamento:

(iv) Mobilizar e facilitar a participação ativa da mulher nas equipes de manejo de água; (grifo nosso).

18.62. Implícita em praticamente todos os elementos deste programa está a necessidade de melhora progressiva do treinamento e das perspectivas profissionais do pessoal em todos os níveis das instituições do setor. As atividades específicas do programa compreenderão o treinamento e a manutenção de pessoal com conhecimentos em participação comunitária, tecnologias de baixo custo, manejo financeiro e planejamento integrado do manejo de recursos hídricos urbanos. Devem-se tomar providências especiais para mobilizar e facilitar a participação ativa da mulher, da juventude, das populações indígenas e comunidades locais nas equipes de manejo de água e para apoiar o desenvolvimento de associações e comitês da água, oferecendo-lhes treinamento adequado para que se tornem tesoureiros, secretários e encarregados. Deve-se dar início a programas especiais de ensino e formação da mulher, tendo em vista a proteção dos recursos hídricos e da qualidade da água nas zonas urbanas. (grifo nosso).

18.68. Os princípios estratégicos fundamentais para o manejo holístico, integrado e ambientalmente saudável dos recursos hídricos no contexto rural podem ser enunciados da seguinte forma:

(b) As comunidades locais devem participar em todas as fases do manejo da água, assegurando a plena participação da mulher, tendo em vista o papel fundamental que desempenha no abastecimento, manejo e uso em suas atividades diárias; (grifo nosso).

(d) É necessário reconhecer e apoiar ativamente o papel das populações rurais, com particular ênfase na mulher. (grifo nosso).

18.80. É preciso promover ativamente o ensino e o treinamento dos recursos humanos no plano nacional por meio de: (a) avaliação das necessidades de manejo e formação de recursos humanos atuais e de longo prazo; (b) estabelecimento de uma política nacional 
de desenvolvimento de recursos humanos; e (c) início e implementação de programas de treinamento para o pessoal de todos os níveis, bem como para os agricultores. As medidas necessárias são as seguintes:

(d) Treinar pessoal em todos os níveis, inclusive agricultores, pescadores e membros das comunidades locais, com especial referência à mulher; (grifo nosso).

Todos os dispositivos acima listados, extraídos do documento oficial da Agenda 21 Global, demonstram a necessidade e a urgência em capacitar a mulher para atuar na gestão das águas.

\section{Conclusões}

Como vimos, a relação água e mulher vai muito além das questões das políticas públicas ou de ordenamentos legais, sobretudo é algo intrínseco no feminino.

A água se encontra de forma desigual em sua distribuição geográfica no planeta, algumas regiões possuem abundância, outras carecem deste líquido da vida.

Historicamente foi relegado à mulher o papel de prover água para sua família, mesmo que isto signifique caminhar por horas e horas com uma lata d'água na cabeça, para depois, ainda cumprir com seus afazeres domésticos. E esta mulher, treina suas meninas para continuarem sua saga, de forma a comprometer o futuro destas crianças que ficam sem instrução, sem saúde e sem qualidade de vida. Entretanto, apesar da importância do papel da mulher na questão água, esta ainda não tem seu protagonismo reconhecido.

Dados demonstram a ausência de saneamento e as condições precárias de milhares de famílias brasileiras, em pleno século XXI banheiro chega a ser visto com artigo de luxo em muitos lares. E lá estão as mulheres lutando pela água para criar seus filhos e sobreviver.

A força da mulher e da união de mulheres se fez sentir nos dois exemplos de luta pela água, ocorridos na Bolívia e México no início deste milênio, os quais demonstram que por seus filhos e pela vida são capazes de guerrear e sagrarem-se exitosas. A possibilidade de um mercado da água, da privatização da água no Brasil também deve nos preocupar.

Por fim, verificamos que os documentos oficiais sobre Meio Ambiente - ONU favorecem e determinam o protagonismo da mulher na gestão e manejo da água também no Brasil, cumpre agora aos governos, notadamente o brasileiro, fazer cumprir estas determinações e favorecer esta participação qualificada da mulher no cuidado com a água. Temos esperança e força para a luta!

\section{Referências}

Agenda 21 Global (n.d.). Recuperado de: <http://www.mma.gov.br/responsabilidade-socioambiental/ agenda-21/agenda-21-global>

Bertelli, M. et al. (n.d.). La guerra interminable: 15 años de lucha por el agua en Bolivia. El pais. Disponível em: <https://elpais.com/elpais/2015/07/13/planeta_futuro/1436796771_984802.html>

Brasil (2007). Lei da Política Nacional de Saneamento. Recuperado de: <http://www.planalto.gov.br/ ccivil_03/_ato2007-2010/2007/lei/111445.htm>

Campos G., S. I. (2016). Água: uma coisa de mulheres? Recuperado de: <https://blogs.iadb.org/ideacao/ 2016/10/20/3305_agua_mulheres_genero/>

Garcia, L. (2007). Água em três movimentos: sobre mitos, imaginário e o papel da mulher no manejo das águas. Gaia Scientia 1(1), 17-23.

Gómez-Fuentes, A. C. (2009). Un ejército de mujeres. Un ejército por el agua. Las mujeres indígenas Mazahuas en México. Agricultura, sociedad y desarrollo, sept./dic., 208, 207-221. 
Instituto Trata Brasil (2017). Situação Saneamento no Brasil. Recuperado de: <http://m.tratabrasil.org.br/ saneamento-no-brasil>

Monje Silva, A., Núñez, A., \& Subiza, D. (n.d.). A água tem gênero? Recuperado de: $<$ https://publications.iadb.org/handle/11319/7700?locale-attribute=pt\&\#sthash.xtMzHsyo.dpuf>.

ONU (2015). Objetivo 5. Alcançar a igualdade de gênero e empoderar todas as mulheres e meninas. Recuperado de: <https://nacoesunidas.org/pos2015/ods5/

ONU (2015). Transformando Nosso Mundo: a agenda 2030 para o desenvolvimento sustentável. Recuperado de: https://nacoesunidas.org/pos2015/agenda2030/

Silva, E. R .(1998). O curso da água na história: simbologia, moralidade e a gestão dos recursos hídricos. (Tese de Doutorado). Fundação Oswaldo Cruz, Escola Nacional de Saúde Pública, Rio de Janeiro, RJ, Brasil. $212 \mathrm{p}$.

Souza, L.C. (2008) Descobrindo-se água: um olhar feminino. In Heimann et al. (Org.) Nossas Mulheres 2. Jundiaí: In House, 141-145.

Udaeta, M. E. (2001) Bolivia: La Vision y Participacion de las Mujeres en la Guerra del Agua em Cochabamba [Bolivia]. Recuperado de: <http://genderandwater.org/es/productos-gwa/conocimiento-sobre-genero-yagua/guia-para-la-integracion-de-genero-en-la-gestion-integrada-de-recursos-hidricos/estudios-da-casogenero-y-la-girh/bolivia-la-vision-y-participacion-de-las-mujeres-en-la-guerra-del-agua-en-cochabambabolivia/>b 